\title{
Eco-dialogical learning and translanguaging in open-ended 3D virtual learning environments: Where place, time, and objects matter
}

\author{
Dongping Zheng \\ University of Hawaii at Mānoa
}

Matthew Schmidt

University of Cincinnati

Ying Hu

University of Vermont

Min Liu

University of Hawaii at Mānoa

Jesse Hsu

Tamagawa University

\begin{abstract}
The purpose of this research was to explore the relationships between design, learning, and translanguaging in a 3D collaborative virtual learning environment for adolescent learners of Chinese and English. We designed an open-ended space congruent with ecological and dialogical perspectives on second language acquisition. In such a space, sense-making is contingent on the relational dynamics of place, activities, and artefacts. These spaces encourage meaning-making in situ, manipulation of virtual objects within places, and coordination among players. Our investigation looked at how learners of Chinese and English collaborated on a project in which they decorated a virtual living room. The findings suggest that socioculturally bounded places afford unique learning opportunities. Firstly, learning occurred through referencing, which is the mutual clarification of a virtual object's meaning, position, and function, in relatively stabilised places, such as a museum, and secondly, learning occurred through coordination between verbal instruction and object manipulation in more adaptive places, which we call eco-dialogical learning. We also found a strong relationship between translanguaging and object manipulation. We conclude the paper from the perspective of how the eco-dialogical model resulted in designs that promoted cognition and interactivity.
\end{abstract}

\section{Introduction}

This article addresses the confluence of design and learning in relation to space, places, activities, and virtual artefacts in a virtual world (VW) named China World. This VW was built in Atlantis Remixed (ARX), a game-based, 3D collaborative virtual learning environment (3D CVLE) designed for educational tasks. ARX contains "persistent, avatar-based social spaces that provide players or participants with the ability to engage in long-term, jointly coordinated action” (Thomas \& Brown, 2009, p. 38). Our research focuses on the interplay of activity, affordances, and learning within the VW. Our approach is rooted in ecological psychology and is framed within an eco-dialogical perspective of language acquisition. In the eco-dialogical model (Zheng, 2012), the linguistic perspective of communication as negotiation for meaning between two actors is extended systematically to consider also how objects in the environment and sociocultural factors influence meaning-making and realisation of values. The eco-dialogical model can be characterised as the interplay of actor(s), object(s), and action(s) within a socio-historical context(s). From this perspective, language is not simply a means by which we communicate, but also an activity we engage in together that leverages available features of the environment, as well as prior knowledge and experiences.

Specifically, we explore the phenomenon of translanguaging, a novel term we hope can bridge the disciplines of language learning, educational technology, and design. From an eco-dialogical perspective, translanguaging connotes two concomitant meanings. Firstly, it refers to two or more learners dynamically switching between at least two languages (our data involves Chinese and English). Secondly, 
this dynamic interchange between languages and cultures is only considered translanguaging when learners are doing something together. Our definition puts doing things together at the fore, as a first order event. This differentiates translanguaging from code-switching, a phenomenon that has been widely addressed by the applied linguistics community, and for which language is at the fore of investigation.

Code-switching implies a monolingual perspective that treats different languages as separate, discrete, hierarchical systems (Cook, 1999). From this perspective, bilingual/multilingual speakers’ dynamic intermingling of multiple languages reflects language interference, and is perceived as a deficiency in linguistic competence (Berthold, Mangubhai, \& Batorowicz, 1997; Sounkalo, 1995). However, with increasing awareness of the distinction between monolingualism and bilingualism/multilingualism, researchers have begun to develop newfound respect for multilingual linguistic variations (Canagarajah, 2011a; Garcia, 2009). The term translanguaging was developed to more clearly designate language learners' fluid use and refinement of all meaning-making resources from their entire linguistic repertoire (both L1 and L2), so as to coordinate a flow of real-time linguistic activities. From the perspective of translanguaging, fluidly switching between languages during shared activities is not viewed as a sign of deficiency in language competency. Rather, it embodies the speaker's sociocultural and historical knowledge of linguistic resources, as well as the speaker's perception of the environment in which the coordination takes place. In such a learning ecology, boundaries between native speakers and non-native speakers become blurred. All speakers are able to draw from multiple languages for communicative purposes (Canagarajah, 2011a, 2011b) and, therefore, wield some degree of agency, regardless of L2 ability.

The aforementioned translanguaging is a momentous step beyond the view of language as a set of disembodied codes (Love, 2004) and conceives of language as something that is constantly acquired, learned and refined. Further, from an eco-dialogical view, language is but one of many semiotic resources that can be appropriated in coordinative activities. Languaging is something we do together (Cowley, 2011); translanguaging is something persons from different cultures who share a language (either native or otherwise) engage in when they do something together (Zheng, 2012). It embodies the intrinsic foregrounding of coordinative activities over language alone. Hence, a highly salient context and a shared activity within which translanguaging can emerge are prerequisites to the phenomenon. For the sake of theoretical congruence, we refer to this as eco-dialogical translanguaging and to the other as linguistic translanguaging.

Given the primacy of linguistically and culturally salient environments with which eco-dialogical translanguaging could co-arise, particular attention must be given to where activity transpires; hence, we explicitly define our usage of the terms "space" and "place." A space is defined by its common meaning - a neutral three-dimensional expanse. A place, on the other hand, is viewed as a discrete, specific space that holds a deeper sociocultural meaning and is accompanied by notions of social practice and function (Harrison \& Dourish, 1996).

Place is a critical component of eco-dialogical translanguaging; however, classrooms lack the necessary contextual factors required for eco-dialogical translanguaging to emerge. Learners can only pretend to be where the target language is spoken. Classroom activities based on pretence usually cannot provide for manipulation of material artefacts or collaboration with L2 speakers (Valleman, 2008). One's sense of place is socially constructed by both one's background and experiences, as well as repeated engagement and consequent identification with the space (Ingold, 1993; Schultze \& Boland, 2000). Therefore, VWs can embody the real world meanings of built environments (Cowley, 2002; Velleman, 2008; Zheng, Young, Brewer, \& Wagner, 2009) and thus enable students to directly perceive and act upon the environment. Collaboration and interaction between L1 and L2 speakers in VWs are multidimensional and action-oriented. VWs afford not only joint action (Thomas \& Brown, 2009) and negotiation for action (Zheng, Young, Wagner, Brewer, 2009), but also materialised action (Velleman, 2008) and translanguaging (Zheng, 2012).

Extending the notion of social construction of place to a more micro-scale of multimodal analysis, putting place at the fore of an investigation can help us understand learning (Zheng, Dai, \& Liu, in press). In the case of VWs designed as places, language learners' interactions go beyond reciprocal utterances to language-facilitated coordination. Language learners are brought into the VW-as-shared-place where they are able to jointly coordinate to work on the same projects involving virtual objects and see the results of 
their collaboration unfold in real-time. Looking systemically at the collective result of learners' microscale actions and languaging events in these places characterizes learning as a form of distributed cognitive events (Järvilehto, 2009; Steffensen, Vallée-Tourangeau, \& Vallée-Tourangeau, 2016), or place-taking events (Zheng, Dai, \& Liu, in press). Place-taking highlights the natural and sociocultural specific layout of features and resources within a given place. Place-taking characterizes learning as the totality of change in the non-linear knowing process, comprised of the knowing phases of unraveling the knot, knowing the way and penetrating through based on the nature of action, place and dialogical relationships (Zheng, Dai, \& Liu, in press). These knowing phases take place in sequential order when looking at problem-solving events as a whole, and result from action-taking events. Therefore in the context of this work, we define learning as an observable eco-dialogical result of place-taking actions. Similarly to how we differentiate linguistically-oriented translanguaging from coordination- and actionoriented translanguaging, we characterize this place-taking learning as eco-dialogical learning.

\section{Conceptual framework}

\section{The eco-dialogical model}

The eco-dialogical model (Figure 1) was proposed by Zheng (2012) in her research on a 3D CVLE called the Second Life Chinese School, in which she integrated ecological psychology (Gibson, 1979; Thibault, 2011) and dialogical perspectives (Linell, 2009) to explore how Chinese language learners made use of linguistic signs and virtual artefacts to make meaning and take actions together.

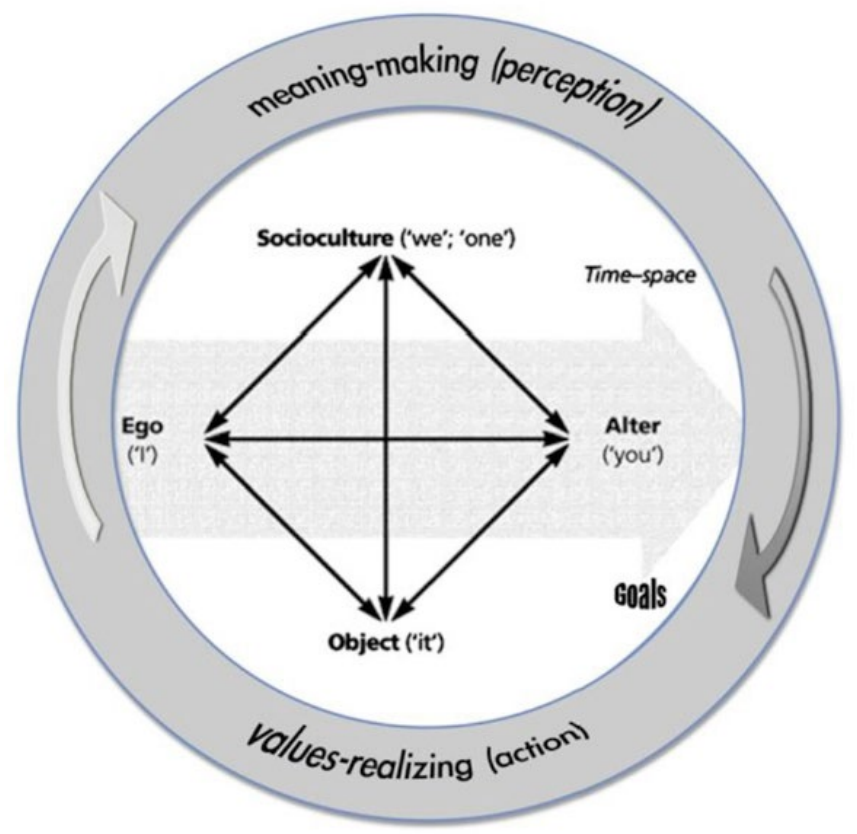

Figure 1. Eco-dialogical model (AUTHOR, 2012a)

There are four coordinates of communication in the eco-dialogical model. They are:

1. ego (I), which is the speaker him/herself.

2. alter (you), which is the self's direct interlocutor.

3. object (it), which is the referent(s) of the action;

4. socioculture (we, one), which comprises "meditational means like language, cognitive and other artefacts, as well as socially shared knowledge of the world” (Linell, 2009, p. 95).

This model accounts not only for the interlocutors (ego and alter) but also for the visible (object) and invisible (socioculture) references of interaction in communication. In this study, the term object is used to refer to those virtual objects that are in relation with the actors. Objects and actors are in turn related to 
the two core concepts that are fundamental to our design and analyses: the perception-action cycle and affordances.

\section{Distributed language and eco-dialogical translanguaging}

Ecological psychology (EP) attaches great importance to appropriate analysis of the environment in explaining perceptually guided actions (Gibson, 1979). The EP perspective promotes a cyclical conception of perception and action. Specifically, perception is conceived of as being supported by exploratory actions characterised by "scanning for and use of information" (Thibault, 2011, p. 220). Further actions are carried out based on perceived information. This continuous mutual engagement between perception and action allows organisms to organise to regulate their behaviours.

The perception-action cycle frames the general notion of language as something we do together (i.e., languaging), rather than transmission of ideas by decoding lexicon-grammar representations (i.e., language) (Cowley, 2011). In this view, language is a supplement to action-oriented cognition, as opposed to a primary and universal system built in the mind (Love, 2004). Languaging is an earlier emergence than the bilingual notion of linguistic translanguaging, with roots in distributed language. Distributed language highlights the interplay of cognition and communication. In distributed language, linguistic resources are only one piece of the many resources humans use to regulate encounters with the environment and history of experience (Järvilehto, 2009). Distributed language views languaging as firstorder activity that dynamically occurs right here and now, specifically for coordinating activities. This view moves away from the cognitive model of language processing in isolated, often decontextualised, language-focused tasks. Instead, languaging is seen as a way of coordinating first-order dynamic activities. In distributed language, vocabulary is considered second-order. This re-thinking of language systems as distributed has pushed the fields of both cognition and linguistics to a third wave of cognitive science that softens the boundary between subjectivity and objectivity, stabilised prescriptions and dynamic interactivity (Steffensen, 2012). In this view, the embodied experience of doing things together becomes the starting point of design and learning (c.f., Dewey, 1905).

\section{Affordances and the perception-action cycle}

In the eco-dialogical model, an affordance can be manifested in perception-action with actual and 3D virtual objects, as well as linguistic references of action. Van Lier (2006) defines affordances from a language acquisition perspective as "possibilities for action that yield opportunities for engagement and participation that can stimulate intersubjectivity, joint attention and various kinds of linguistic commentary” (p. 81). A chair itself cannot be considered as an affordance in this framework, but rather it has an affordance for sitting given appropriate social situations. An environment can be full of semiotic resources, yet what we perceive is not the resource as it is, but as it relates to us (Reed, 1996; Van Lier, 2000, 2006). Only when an actor perceives and takes action on a resource can it be considered an affordance.

Perception and action are inherently meaning-making and values-realising. The full cycle is required to have an engaging learning experience that yields transformational eco-dialogical learning results. This covaries with transformation of the community, propelled by synergistic values-realising events (Newgarden, Zheng, \& Liu, 2015). Verbalising with synchronised avatar action, attending to game rules, and coordinating future actions contributes to dual values-realising. The full cycle of meaning-making and values-realising stresses action. Action is not stressed merely as activity suggested by acts of speech, but in actual movement, in coordination of social events in which linguistic actions are embedded, and to which social and ecological events give rise.

The notions of perception-action cycle and affordance are informative for analysis of linguistic actions and language development. Agents' perception is constantly being refined in any given ecological niche (Newgarden \& Zheng, 2016; Reed, 1996; van Lier, 2006). With the recurrence of perception-action cycles, learners can detect the increasingly subtle and specific information that serves to further regulate behaviour. When looking into an agent's linguistic activities, it is necessary to identify the persisting or invariant features that promote the aggregated pattern of behaviours as mediated by situation and place (Baldry \& Thibault, 2006; Reed, 1996). Understanding where and how these patterns occur has implications for designers in their efforts to cultivate learning. 


\section{The project}

This project stemmed from a larger project detailing the design of a VW called China World in ARX. China World's layout, topography, and functional, culturally-relevant buildings (i.e., apartment buildings, tea house, theatre, etc.) are the result of team effort between researchers (authors 1 and 3), the ARX project team's 3D universe administrator and world designer, Scott Miller, and his apprentice, Paul Lunny. The participatory design was carried out between the team of researchers and language learners from two high schools in the U.S.A. and Mainland China.

\section{The design}

To foster eco-dialogical learning, we applied design principles from other game-based learning environments, such as (1) transformational play (Barab et al., 2010), (2) possibility spaces and emergent problem solving (Squire, 2008), and (3) design for caring, translanguaging, and encouraging spontaneously emerging problem solving places (Zheng, 2012). Transformational play (Barab et al., 2010) refers to players' embodiment of a role-playing persona to transform players' conceptual understandings. Possibility spaces (Squire, 2008) assign value to the open-endedness in which "players develop knowledge through performances in them, the meanings of which are then reflected upon, negotiated and given legitimacy through participation in interpretive communities" (p. 172). To adopt a similar sandbox-quality of play, we gave users rights to build and edit virtual objects in the virtual space. Promoting a sandbox-quality of play was intended to promote a third set of principles: caring, translanguaging and encouraging spontaneously emerging problem solving places (Zheng, 2012).

These principles were embodied in China World through activities that required coordination between learners. Coordination promotes prospective translanguaging and involves action. Information and objects acquired from other worlds have situated meaning specific to their original locations and contexts. When used in different places, they need to be re-programmed, moved and appropriated to their own cultural and social functions (Dufva, 2013). Caring assumes dialogical consciousness of participants constantly checking on each other's statuses and moves, which promotes careful coordination linguistically in their L1 or L2, and actionally in their avatar movements, object manipulations, and collaboration on a project. Caring also fosters attention to sociocultural norms, practices and places. Coordination, which involves active manipulation of virtual objects, is used as a vehicle to promote caring and translanguaging in our design, which further promotes novel and spontaneous experiences (Dewey, 1905).

An example of design for transformational play from China World that positions person, content and context inter-relationally (Barab, Gresalfi, \& Ingram-Goble, 2010) was the careful selection of culturallyrich environments, such as a teahouse, a courtyard with art on display, an apartment building, the Great Wall, and the Silk Road (Figure 2). These built-environments were placed in the VW with a rough geographical alignment to actual geographical locations and regional customs. Geographical location embodies meaning, which is to say that meaning making is context-specific. In a similar vein, an ecodialogical perspective assigns meaning to places. An example of design for spontaneous emergent problem solving is apparent in that we purposefully did not provide participants with sequenced quests leading to larger mission goals. Rather, we left the decision-making of what to accomplish to the participant designers. Choosing what to do for the next session usually occurred at the beginning and end of each session, at which time reflection and planning were negotiated between the students and the researchers.

\section{The activity}

Participants in this study undertook a co-decorating activity. This activity was designed for American and Chinese students to get to know each other before they started to design quests and missions. Our goal was to help them learn to coordinate by using multimodal communication channels, such as text chat, audio conferencing, and file sharing. Rather than a traditional introduction of telling each other who they were and what they liked, we used the features of the VW while encouraging learners to get to know each other's communication and action habits. To support their coordination, we provided them this list in both English and Chinese: 
1. American students teach the Chinese student the basics of world-building

a) Right-click any objects you see

b) Highlight and copy the model name

c) Paste object names in a .txt file on your desktops

d) Then you can just copy a name from the list and then paste it into a new object in China World

2. Plan together what kind of room you want to decorate; it could be a classroom, a living room, a game room, a reading room, a kitchen, etc.

3. Discuss what you both want for your room, what furniture, decorations, utilities, animals and Non-playing characters (NPCs)? You can only have the following:

a) 5 pieces of furniture

b) 6 pieces of wall decoration

c) 15 pieces of utilities, such as a lamp, teapot, pencil holder, Chinese wok, etc.

d) 2 small pets

e) 2 Non-playing characters (NPC)

4. Write down the name of the objects that you have discussed on the text file or on Google Doc, and go to the Junk Yard or the Courtyard Museum to find them, then paste the objects' name (follow step 1)

5. Go back to your room in and start decorating

The crux of this activity was to get pieces of artwork from the Courtyard Museum's collection and bring them back to participants' rooms as decorations. The pivotal events took place in two sequential places: the Courtyard Museum and Apartment Building. Figure 2 illustrates the distance between the two places in the VW. In the Courtyard Museum, participants coordinated to choose artwork that they liked and pasted associated information into their notebooks. Following this, participants flew their avatars to the Apartment Building and added the art to their own apartment. Participants would coordinate on choosing and placing artwork and on the technical aspects of editing the VW.

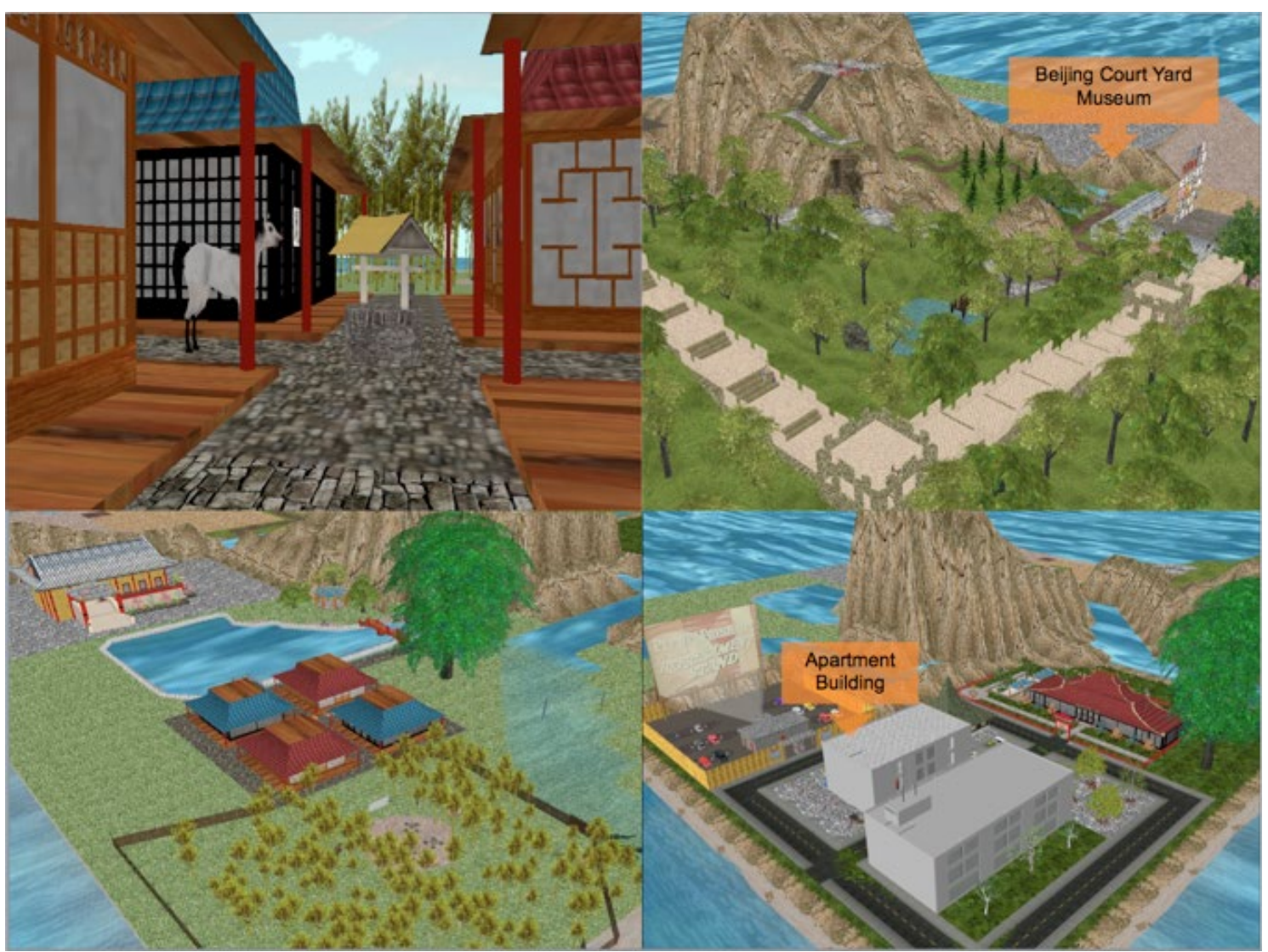

Figure 2. Screenshots of the 3D China World showing the Courtyard Museum and the Apartment Building where the main quest activity took place. 


\section{Methodology}

The purpose of this research was to explore the relationships between design, learning and translanguaging in a 3D collaborative virtual learning environment for adolescent learners of Chinese and English. Two research questions guided our inquiry. Firstly, how does learning occur in China World's socioculturally rich places (e.g., Courtyard Museum, Apartment Building)? Secondly, how does translanguaging occur in two-way exchanges in a collaborative virtual coordination activity?

\section{Participants}

Three American learners of Chinese from a school in the western United States and one Chinese learner of English from a middle school in Mainland China volunteered to participate in the collaborative decorating activity. Participant profiles are provided in Table 1. The American students participated in the project from their school computer lab and the Chinese student from her mother's office desktop computer for this particular session. Authors 1 and 3 alternately facilitated the collaboration from the participating school in the U.S.A.

Table 1

Participant profiles

\begin{tabular}{lllllll}
\hline Name & Age & Gender & Nationality & Ethnicity & L1 & Yrs learning L2 \\
\hline Anan & 17 & F & Chinese & Asian & Chinese & 3 \\
Lily & 15 & F & American & Asian & English & 3 \\
Kate & 15 & F & American & Caucasian & English & 3 \\
Jo & 16 & $\mathrm{M}$ & American & Asian & English & 3 \\
\hline
\end{tabular}

\section{Data collection and analysis}

This study sampled data from 8 weeks of collaboration between the three American students and one Chinese student. Each week, three to eight sets of video data were collected, including each participant's and the researcher's screen, captured using screen recording software Screenflow's (2014) picture-inpicture function (see Figure 3), and two high definition video recordings of American participants in the school lab. Each video lasted between one to two hours. The data for the current study was purposively selected from the third session and consisted of three one-hour recordings of participants' screens and videos from the school lab.

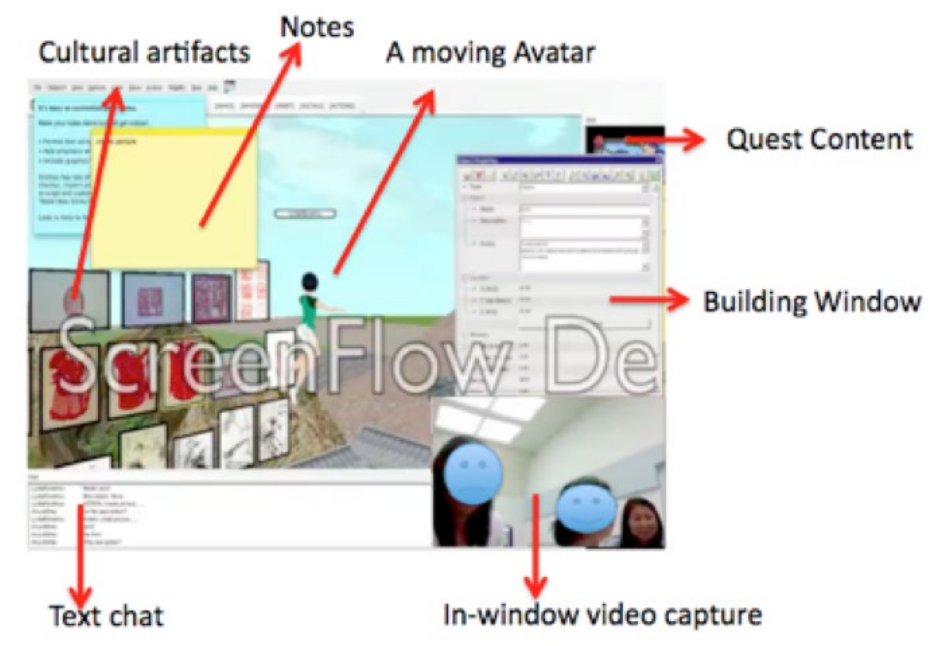

Figure 3. The multimodal functionality of the world and Screenflow screen-recording layout. 
Screen recording and participants' live recordings were synchronised using an All-Views-QualitativeAnalysis approach (Goggins, Schmidt, Guajardo, \& Moore, 2011) in Transana (2014), a software tool that supports multimodal transcription and analysis, and thus present the actual situation during the activities from various angles. Because the Chinese student participated in her mother's office where there was no video camera, her activities could only be observed from her VW avatar actions. After videos had been synchronised, they were transcribed using Transana. Four modalities were transcribed separately, but synchronised with Transana timecode function for multimodal analysis (Baldry \& Thibault, 2006): (1) American students' avatar actions and their physical actions, (2) all students' avatar actions, (3) all students' verbal communication, and (4) text chats. Transcribed speech and action-sequenced data were then analysed in Transana.

After multimodal transcription, we segmented the transcripts linked with video clips into projects. "A project is dynamic through its course-of-action; it progresses through different phases or moments, such as planning, development, performance and retrospective evaluation" (Linell, 2009, p. 190). A communicative project consists of a minimum of three conversational turns as the unit of analysis: A, B, A. For example, Participant A initiates the interaction with an action that includes, but is not limited to utterances, and thereby indicates a targeted understanding. Then Participant B must indicate his/her understanding of this by some responsive action. Then Participant A has to show her/his reaction to Participant B's response by yet another action. This action (which can be the same or different from B's expectation) closes a communicative project. Any instance of $\mathrm{A}, \mathrm{B}, \mathrm{A}$ is considered to be a Communicative Project (CP). While a CP can be as short as three turns, CPs can also be characterised as long chains of interactions required to complete a task. While Linell's CPs focus more on discursive turns. Our segmentation of CPs was based on the eco-dialogical model, in which communication can be understood as project-in-action. Both discursive turns and avatar movements are counted for CP segmentation, which aligns our definition of (trans)languaging.

After data were transcribed and segmented into CPs, we assigned keywords to the CPs. For quantitative analytical clarity, we describe now how translanguaging and objects were coded. The first and third authors coded the interactions separately and then discussed their analyses until reaching final agreement. This coding method has been used elsewhere (e.g., Newgarden \& Zheng, 2016; Newgarden et al., 2015; Zheng, Dai, \& Liu, in press; Zheng, Newgarden, \& Young, 2012). We describe this highly grounded, contextualizing, and eco-dialogical theory-driven technique as abductive coding. Translanguaging Instances (TI) were coded based on two conditions within each CP: (1) they had to be embedded within each CP; and (2) they must include a switching between L1 and L2 utterances. Both speech and action modes were considered equal turns. This analytical decision was made based on the theory of CP that both action and verbal language-in-action are ways of coordinating. Examples of action include avatar movement, the direction where the avatar is facing while speaking, avatar gestures, and so on. Within each CP, translanguaging and objects were also assigned codes. The coded CPs were then exported in spreadsheet format as numerical categorical data. Since Transana's categorised data has values of 1 or 0 , those TIs assigned with values of 1 on object keywords were further categorised with one object (1) or more than two objects (2) manually.

It might be helpful to consider the following analytical nuances since there was an unequal number of participants in both parties. The switching between L1 and L2 can take place either within one's own turn sequence, or members' turn sequences in a party. In this paper, only the American party members' translanguaging is treated this way since there was only one Chinese participant. In essence, the American party was considered as one person. For example, when Lily’s utterance of Chinese was followed by Jo's English within one CP, then the switch is accounted as one TI. Although each TI is a single utterance, the context in which they occur can be at least three turns.

\section{Findings and discussion}

\section{Learning in China World's socioculturally rich spaces}

To answer the research question of how learning occurs in China World's semiotically- and socioculturally-rich spaces, we relied on qualitative observation and multimodal verbal and action examples. Multimodal analysis suggested that different learning resulted from the ecological niches of different places. Table 2 shows the duration and the type of activities that took place in the two locations. 
Table 2

Learning within two places of China World

\begin{tabular}{lll}
\hline Places & Duration & Activities \\
\hline $\begin{array}{l}\text { Beijing Courtyard } \\
\text { Museum }\end{array}$ & 23.2 minutes & $\begin{array}{l}\text { Chose some works of art; } \\
\text { Attempted to teach Anan how to use "action” script with } \\
\text { verbal instruction. }\end{array}$ \\
$\begin{array}{l}\text { The Apartment } \\
\text { Building }\end{array}$ & 37.1 minutes & $\begin{array}{l}\text { Put up the artwork on the living room wall; } \\
\text { Solve “action” script problem in action; } \\
\text { Rearrange the artwork. }\end{array}$ \\
& &
\end{tabular}

Learning through verbal instruction and referring.

The following interaction captures the beginning (CP1) and tail end (CP2) of a translanguaging sequence in which Americans taught Anan the importance of copying an ActionScript.

CP1: (0:18:12.6) $-(0: 20: 02.6)$

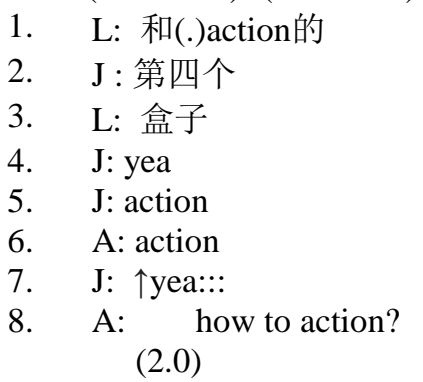

3. L: 盒子

The one with action. The fourth...

Box.

9. J: click the picture

10. L: yea

11. L: 看到吗？

Can you see it?

(1.0)

12. L: anyu, 你(.)你看到, 那个盒吗?

Anyu, can you see that box?

13. A: 那个? $\mathrm{Um}$, that one? ${ }^{\circ} \mathrm{Um}:::\left[(. \mathrm{hhh})^{\circ}\right.$ ]
14. J: [第四个盒]

15. $\mathrm{L}:>\uparrow \mathrm{so}$, 你右击的时候, <有一个蓝色

16. DP: 的窗口

17. L: 的窗口

18. A: is this?

19. A: oh, oh, $\downarrow$ sorry

20. A: ${ }^{\circ} \mathrm{hmm}::^{\circ}$

21. A: sorry. (3.0)

In CP1, Lily and Jo pointed out to Anan where the Action field is in the world-building window by referring it as the fourth "box" (field). They mainly refer to the world-building window and the action field in Figure 3, which both parties can see on their individual screens to find common ground (Dufva, 2013; Newgarden et al., 2015) (Lines 1-6). This was achieved by using indicational language, such as, “Can you see that box?” (Line 12) and “That one?” (Line 13). 
In CP2, Kate and Lily explained to Anan the reason why ActionScript is needed in order for the painting to display correctly.

CP2 (0:25:50.1)-- (0:26:37.2)

1. A: why, why use action?

2. K: what?

3. L: 因为如果你只拷贝名字，你摆(.)摆在卧 室的时候, 额, 没有画, 只有蓝色的 (.)picture ((laugh))

4. A: $\uparrow$ uh? 没听懂

Because if you only copy the name of the painting, when you put it on in the living room, uh, (there will be) no paintings, but only blue picture.

Huh? I don't understand.

5. K: That's ok.

6. A: Sorry.

7. L: Because if you only take the model, then when you put it into the room

8. K: >It won't work<

9. L: It is just gonna be blue. There won't be a picture.

After more scaffolding using text chat, screenshots and explicit language, Anan understood that input in the Action field is needed for putting up the paintings. However, she did not get the point of "why use action" (Line 1). Even with Lily's explanation in both Chinese (Line 3) and English (Line 7), Anan left the courtyard photo gallery for the Apartment Building without a full understanding of "why use action", but we can infer from the multiple data points that she knew "it won't work" (Line 8) if the action field was programmed incorrectly or left empty. We cannot detect from the data that Anan responded verbally that she understood what Lily was explaining (Lines 7 and 9). We could only conjecture this inference since she did not pursue "why use action" with further questions.

CP1 and 2 provide a salient glimpse into a notable event in this museum activity: the teaching of ActionScript. American learners had been engaged in teaching Anan the basics of building in the VW before this episode. Both parties had also successfully put in furniture and other utilities, which did not require more advanced programming, such as using ActionScript. The American learners used their knowledge and building experiences to instruct Anan that she also needed to copy the ActionScript from the paintings she chose in addition to the file name. The event of making sure that Anan copied down the ActionScript was directional and verbal. There were both dialogues and manipulation of objects involved, but they were at the scalar level of choosing a picture, a core function of the museum space. In this project, eco-dialogical learning was achieved by trusting the foreseeable result that "it won't work" experienced by the American party, but this tacit understanding was tested in the later actual action event in the following sessions.

Learning through verbal instruction and manipulation

The American party's direct teaching of programming ActionScript was successful in the Courtyard Museum where Anan learned that she would have to do something with ActionScript. However, this tacit knowledge did not become procedural knowledge until Anan engaged in manipulation in the Apartment Building.

CP3 (0:36:17.5)- (0:36:49.1)

$\begin{array}{ll}\text { 1. } & \text { L: Um::: 用右边的猫 } \\ \text { 2. } & \text { A: }{ }^{\circ} \text { 恩 } \\ \text { 3. } & \text { L: 变成你喜欢的画. } \\ \text { 4. } & \text { J: ((nodded)) } \\ \text { 5. } & \text { L: ((wiggles fingers of both hands)) } \\ \text { 6. } & \text { J: } \uparrow O h \\ \text { 7. } & \text { L: }{ }^{\circ} Y e a{ }^{\circ} \\ \text { 8. } & \text { J: She did it. } \\ \text { 9. } & \text { L: } \uparrow O h\end{array}$

Um, use the cat on your right.

$O K$.

Change into the painting that you like. 
10. J: ((turn to the other side))

11. K: Um::::wait. go on that side and see if it has the thing on there?

12. J: $\downarrow$ ha

13. J: ((Closed his eyes, turn his head, very disappointed))

14. L: ${ }^{\circ}$ probably she is, maybe she is still pasting it, $\mathrm{so}^{\circ}$

15. $\mathrm{K}:=$ Yeah. ${ }^{\circ}$ maybe it's that ${ }^{\circ}$

CP3 captures the beginning event when they flew back to the Apartment Building. After making sure that Anan remembered to the procedure (lines 1-9 below), Lily made an attempt to get Anan to change to the picture from one of a cat (line 12). Although a picture frame appears (but without the picture and it looks like a fuzzy screen), this shows only partial procedural knowledge. From this result, the American party knew something was wrong with the action field's programming, but they did not know what procedure Anan had missed; the American party did not know whether she copied the ActionScript in the museum or simply did not understand the need to paste the ActionScript to the Action field.

In CP4, the American party, predominately Kate, initiated a series of hypotheses to identify where the actual problem was. These hypotheses were seemingly co-acted with Jo using both verbal and action modalities.

CP4 (0:37:25.6)- (0:38:05.6)

1. K: Actionnn:::

2. $\mathrm{K}$ : ok (.) how do we write that so it is comprehensive?

3. $\mathrm{K}$ : >coz i don't think she knows how to use that action<

4. J: 你拷贝Action后的字吗?

5. J: ((looked at L))

6. J: 个字?

7. L: ((nodded))

8. A: Um::: OK

9. J: Did you?

10. L: She said OK.

11. K: OK. ${ }^{\circ} \mathrm{I}$ don't know ${ }^{\circ}$

12. J: ${ }^{\circ}$ Well, did she, hmm (hhh) ${ }^{\circ}$

13. K: Wait, she gonna copy action from this thing or?

14. $\mathrm{J}:=\mathrm{I}$ don't know. (Is there action)

15. J: ((reached his left hand to the mouse))

16. K: I think we were supposed to tell her to [paste the action]

17. K: [((right hand opens up and pointed to the screen))]

18. J: ((right clicked the fuzzy screen))

19. ((Building window appeared as a result of J's right click)) (0.29)

20. ((Fuzzy screen disappeared))

21. $\mathrm{J}: \uparrow \mathrm{OH}$

22. L: $\uparrow$ Oh:::

23. L: ((Laugh))

The pivotal action was between Jo and Anan (Lines 4-11), in which they realised Anan might realise that she forgot to or did not copy the ActionScript from the original painting in the museum. When nothing happens, the American learners keep their focus on what they think Anan might be doing. While Jo and 
Lily seem to negotiate what "Ok" means (Lines 11-12), Kate wonders if she copied action from the right place (Line 13) in an attentive turn displaying her awareness of interaction between Jo and Lily.

CP5 displays the dynamics of a successful ending. At this point, something surprising happened: the fuzzy screen disappeared. They did not understand why but were pleased. Now they were waiting to see what was going to happen.

CP5 (0:38:07.0)- (0:38:25.0)

1. ((the fuzzy screen disappeared from the wall))

2. $\quad$ J: > I didn't do anything<

3. L: It wasn't you.

4. A: 哦

$\mathrm{Oh}$.

5. $\quad \mathrm{J}$ : I was going to see if she copied it.

6. $\quad \mathrm{J}:{ }^{\circ} \mathrm{I}$ think she would copy the name ${ }^{\circ}$

7. ((Chinese painting appeared on the wall))

8. L: Ah?

9. $\mathrm{K}: \uparrow \mathrm{YEAH}$

10. $\mathrm{J}:=\uparrow W o w$

11. L: It was not the picture but $\uparrow$ Yeah

12. $\mathrm{J}: \uparrow W o w$

This change of affordance layout (i.e., disappearance of the fuzzy screen), gives the learners a much stronger confirmation than Anan's verbal "Umm, Okay," (in CP4, line 8) that something is going to happen. The disappearance was not the result of Jo's action (line 2), but rather Anan's re-programming of the Action field. Anan's use of the Chinese "Oh" affirmed her own realisation as well the American party's confidence. Overall, this use of a traditional Chinese response cry, "Oh," suggests that she knows how to go on. A Chinese painting appeared on the wall, 290 milliseconds after the disappearance of the fuzzy screen.

In the above two scenarios, both VW places had a significant impact on Anan's learning to put up paintings. The learning occurred in the Apartment Building was manipulative, that is, Anan fully completed the activity goal with a concrete piece of artwork of her own choice on the wall. In terms of learning, the Museum activity is consequential to the result of the activity. The activity is not learning about places, but happens within places so that learning can be situationally contextualized and values realising, that is, respecting learner's experiences, cultural background, and communicative patterns by using both L1 and L2 in making sense of things.

\section{Translanguaging in the presence of objects}

We observed that translanguaging is usually coupled with the presence of objects either in the case of referring to them or manipulating them. This observation motivated us to test whether there is a statistically significant relationship between translanguaging events and objects. If so, how does it take place? This question aims to explore the learning dynamic present within VWs that are designed around socioculturally relevant play, coordination, and problem-solving. The underlying principles of this kind of learning, afforded by the specific ecological niche of such work, can be applied in other environments.

Relationship between materiality and translanguaging: Chi-square test. All CPs were reviewed to find instances of translanguaging (TI). Our analysis uncovered 96 translanguaging instances and 63 nontranslanguaging instances. To examine the relationship between categorical variables, the number of objects and translanguaging, a chi-square test was applied and its results $\left(\chi^{2}=20.83, \mathrm{p}<.001\right)$ indicated that these two variables are significantly related.

Table 3 shows the pattern of frequencies. From this, we conclude that the two variables are statistically related. When the number of objects is greater than two, translanguaging tends to occur more often. In sum, more objects are positively associated with the occurrence of translanguaging. In other words, when activities are designed around manipulation of objects, such as the artwork selection in the Museum, more translanguaging tends to occur. However, embedding objects alone is insufficient to promote this 
phenomenon. As is evident in the Project section of this article, design and activities are very much dynamically interrelated and interdependent.

Table 3

Contingence table of the number of objects and occurrence of translanguaging

\begin{tabular}{cccccc}
\hline & & \multicolumn{5}{c}{ Number of objects } \\
\hline No & Translanguaging & 0 & 1 & 2 & $\chi^{2}$ \\
Yes & Observed Frequency & 8 & 41 & 14 & $20.83^{* * *}$
\end{tabular}

Note. $* * *=p \leq .001$

These results suggest that more objects are associated with translanguaging. This raises the question of how this is possible. The process of the American students instructing their Chinese partner on what to do is a process of them exploring more complex, subtler, yet at the same time clearer relationships among the objects via their actions-including utterances. As shown in CP1, it is evident that in the American party's attempts to articulate what exactly Anan needed to do, they were constantly refining their perception of the environment that contains the target object.

A closer look at CP1 is in order, so as to demonstrate how both parties translanguage to teach and learn "how to action" (Line 8). In CP1, Lily and Jo were trying to tell Anan where to find the action fields. They started by directly calling out the name of the field "action" and referring it as the fourth box in Chinese (Lines 1-2), and then switching to English to specify the Action function of the box. This was done in relation to the object properties window under the assumption that all parties were looking at the same window. However, after Anan indicated that she did not know how to find the action box with the question "how to action" (Line 8), Jo zoomed out from merely looking at the window to referring to the previous step “click the picture”, which was seconded by Lily's comment "yea”. Then, Jo confirmed that Anan did not see the box by switching from English, "Click the picture” (Line 9) to Chinese, “So, 你右击 的时候, 有一个蓝色 (When you right click, there is a blue)” (Line 15). Jo repeated a more fine-tuned statement, "the fourth box" in Chinese while Lily further integrated Jo's previous comment "click the picture" with another piece of new affordance information "the blue (window)" in Chinese into her instruction: "When you right click, there is a blue (window)." This provides Anan with new affordance information by involving more objects (the picture, the emergence of the object property window, the position of the desired box, the name of the box) to her perception. By integrating previous events (rightclicking the picture) to the current event, it also reflects the dialogical nature of translanguaging.

In light of the eco-dialogical framework, we explain the how process that aligns with AUTHOR'S (2015) theorising on the sequential nature of World of Warcraft gamers' taking careful, skilled linguistic actions. The sequence starts from aligning common ground by referring to virtual objects indicationally or in predicative language. It is followed by prospective actions in which players make an actual move or linguistic move towards the common goals. The sequence is usually closed by taking coactions when parties of play are synchronised in both linguistic and actual actions with no negotiations present. This example reflects the common group alignment in two layers. Firstly, the American party related the target object with other objects in the environment to find common ground with Anan. For example, in the ARX graphical user interface they align Action, the fourth field, picture, window and the third in the popup Building window. In this case, when more objects are involved, more relationships among different objects can be perceived. By relating objects with each other, more ample affordance information is available, increasing the possibility that desired actions will occur. The second layer lies in players' refined perception of each object by differentiating it from others. For example, window is modified by blue in CP1 line 15; Action is differentiated by its blue. The objects also embody historic information for the players to draw upon via their utterances and not only as tangible physical references. For example, Lily pointed out that Anan needed to right-click the picture to get to the blue window. In sum, objects function as tangible references and provide players with enhanced visibility of each change of action that calls for multiple mutual repertoires of linguistic resources (such as Chinese and English in this instance). 


\section{Conclusion}

There is a need to understand how the design and implementation of immersive spaces affect the learning experience, especially from eco-dialogical and distributed language perspectives. This research attempted to address this need by exploring the relationships between design, learning and translanguaging in the China World 3D CVLE. In this paper we have provided descriptions of our design and data analysis which, combined, suggest that China World's design provided opportunities for both meaning-making (perception) and values-realising (action) through coordination of virtual object manipulation. It is through this process that multiple repertoires of semiosis were combined and employed.

First, eco-dialogical learning occurs when place-taking events are encouraged by design and afforded by the socio-institutional norms. Our findings suggest that learning takes place differently in different sociocultural spaces. Firstly, learning occurred through referencing, which is the mutual clarification of a virtual object's meaning, position, and function, in relatively stabilised places, such as a museum. Secondly, eco-dialogical learning occurred through coordination between verbal instruction and object manipulation in more adaptive places, such as an apartment room. Based on these findings, we call for designing for diversified learning opportunities so that learners are cultivated to access, take advantage of and responsively adapt emerging situations.

Second, we call for an eco-dialogical translanguaging in which project-based collaboration and coordination is at the fore for cultivating action-based language learning. Participants' active translanguaging patterns reflected their engagement and agency in communication, which transcended the image of language learning from code-based or form-based learning to action-oriented and problemdriven interaction. Our findings suggest that translanguaging is not merely multilingual speakers' random access to their linguistic resources, but instead that it correlates with affordances in ecologically situated events.

The linguistic orientation of translanguaging has its place in classroom activities and social conversations, but it is the creative, novel and spontaneous experiences collaboratively co-created by speakers of different cultures that is illuminating and hard to achieve without a sound theoretical foundation for design. And, importantly, these experiences were cultivated by our participatory design-based research that took into theoretical consideration space and place, and that brought cultural and linguistic differences into a conscious common ground.

Thirdly, while we acknowledge the limitations of a small number of participants and the limited scope of the study, we are excited by the implications of this work related not only to language learning, but also to how designing for eco-dialogical translanguaging might impact learning in general education contexts. We do not suggest that translanguaging practices should be applied as a norm in all language learning contexts. Rather, we recommend applying translanguaging dynamically, based on those interconnected and interrelated factors and values that are at play. Our findings illustrate the applicability of an ecodialogical perspective in the design and investigation of translanguaging in open-ended, sandboxed 3D CVLEs.

Future research might fine tune activities in two conditions: object manipulation between a linguistic homogenous group and object manipulation between two-way bidirectional groups to tease out whether correlation between translanguaging and more object manipulation also holds true for more homogenous groups, i.e., between American learners who share the same L1 and L2. Our findings also prompt future research to look into how participants engage in bi-directional exchange in 3D spaces and places, in which translanguaging as well as other distributed cognitive processes are deemed necessarily and naturally occurring, such as: identifying problems, making judgments, and moving forward with information given or without all information at hand. Such an investigation is worthwhile for exploring how people do things in virtual spaces. Future research should also take into consideration all components present in the full-blown eco-dialogical model, such as joint heterogeneous two-party action, number of objects and sociocultural norms. Based on this, a deeper understanding of how these components contribute (or do not) to translanguaging can be built. 


\section{References}

Baldry, A., \& Thibault, P. J. (2006). Multimodal transcription and text analysis: A multimedia toolkit and coursebook. London, UK: Equinox Publishing Ltd.

Barab, S. A., Gresalfi, M., \& Ingram-Goble, A. (2010). Transformational play: Using games to position person, content, and context. Educational Researcher, 39(7), 525-536. https://doi.org/10.3102/0013189X10386593

Barab, S., Tyler, D., Adam, I.-G., Patrick, P., Kylie, P., Charlene, V., \& Maria, S. (2010). Pedagogical dramas and transformational play: Narratively rich games for learning. Mind, Culture, and Activity, 17(3), 235-264. https://doi.org/10.1080/10749030903437228

Berthold, M., Mangubhai. F, \& Batorowicz, K. (1997). Bilingualism and multilingualism: Study book. Toowoomba: University of Southern Queensland, Australia.

Canagarajah, S. (2011a). Translanguaging in the classroom: Emerging issues for research and pedagogy. Review of Applied Linguistics and Communication, 2(1), 1-28. https://doi.org/10.1515/9783110239331.1

Canagarajah, S. (2011b). Codemeshing in academic writing: Identifying teachable strategies of translanguaging. The Modern Language Journal, 95(3), 401-417. https://doi.org/10.1111/j.1540$\underline{4781.2011 .01207 . x}$

Cook, V. (1999). Going beyond the native speaker in language teaching. TESOL Quarterly, 33(2), 185209. https://doi.org/10.2307/3587717

Cowley, S. J. (2002). Why brains matter. Language Sciences, 24(1), 73-95. https://doi.org/10.1016/s0388-0001(00)00045-0

Cowley, S. J. (2011). Distributed language. In Cowley, S.J. (Ed.), Distributed language (pp. 1-14). Amsterdam, The Netherlands: John Benjamins. https://doi.org/10.1075/bct.34

Dewey, J. (1905). The postulate of immediate empiricism. The Journal of Philosophy, Psychology and Scientific Methods 2(5), 393-399. https://doi.org/10.2307/2011400

Dufva, H. (2013). Language learning as dialogue and participation. In E. Christensen, L. Kuure, A. Mörch, \& B. Lindström (Eds.), Problem-based learning for the 21st century: New practices and learning environments. Aalborg, Denmark: Aalborg University Press.

Garcia, O. (2009). Bilingual education in the $21^{\text {st }}$ century: A global perspective. Hoboken, NJ: WileyBlackwell. https://doi.org/10.1111/j.1467-9841.2009.00423_7.x

Gibson, J. J. (1979). The ecological approach to visual perception. Boston, MA: Houghton Mifflin. https://doi.org/10.4324/9780203767764

Goggins, S., Schmidt, M., Guajardo, J., \& Moore, J. (2011). 3D virtual worlds: Assessing the experience and informing design. International Journal of Social and Organisational Dynamics in IT, 1(1), 3048. https://doi.org/10.4018/978-1-4666-1948-7.ch012

Harrison, S. \& Dourish, P. (1996). Re-place-ing space: The roles of space and place in collaborative systems. In Proceedings of CSCW '96 (pp. 67-76). New York, NY: ACM. https://doi.org/10.1145/240080.240193

Ingold, T. (1993). The temporality of the landscape. World Archaeology, 25(2), 152-174. https://doi.org/10.1080/00438243.1993.9980235

Järvilehto, T., (2009). The theory of the organism-environment system as a basis of experimental work in psychology. Ecological Psychology: A Publication of the International Society for Ecological Psychology, 21(2), 112-120. https://doi.org/10.1080/10407410902877066

Linell, P. (2009). Rethinking language, mind, and world dialogically: Interactional and contextual theories of human sense-making. Charlotte, NC: IAP.

Love, N. (2004). Cognition and the language myth. Language Sciences, 26(6), 525-544. https://doi.org/10.1016/j.langsci.2004.09.003

Newgarden, K., \& Zheng, D. (2016) Recurrent languaging activities in World of Warcraft: Skilled linguistic action meets the common European framework of reference. ReCALL. 28(3), 274-304. https://doi.org/10.1017/s0958344016000112

Newgarden, K., Zheng, D., \& Liu, M. (2015). An Eco-dialogical study of second language learners' World of Warcraft (WoW) gameplay. Language Sciences. 48(March), 22-4. https://doi.org/10.1016/j.langsci.2014.10.004

Reed, E. S. (1996). Encountering the world: Toward an ecological psychology. New York, NY: Oxford University Press. https://doi.org/10.1093/acprof:oso/9780195073010.001.0001 
Schultze, U. \& Boland, R. J. Jr (2000). Place, space and knowledge work: A study of outsourced computer systems administrators. Accounting, Management and Information Technologies, 10(3), 187-219. https://doi.org/10.1016/s0959-8022(00)00006-0

Screenflow (2014). [Computer software]. Retrieved from http://www.telestream.net/screenflow/

Sounkalo, J. (1995). Code-switching as indexical of native language lexical deficiency in Mauritania. Journal of Multilingual and Multicultural Development, 16(5), 403-421. https://doi.org/10.1080/01434632.1995.9994615

Squire, K., (2008). Open-ended video games: A model for developing learning for the interactive age. In K. Salen (Ed.), The ecology of games: Connecting youth, games, and learning (pp. 167-198). Cambridge, MA: MIT Press. https://doi.org/10.1162/dmal.9780262693646.167

Steffensen, S. V. (2012). Care and conversing in dialogical systems. Language Sciences, 34(5), 513-531. https://doi.org/10.1016/j.langsci.2012.03.008

Steffensen, S. V., Vallée-Tourangeau, F., \& Vallée-Tourangeau, G. (2016). Cognitive events in a problem-solving task: A qualitative method for investigating interactivity in the 17 animals problem. Journal of Cognitive Psychology, 28(1), 79-105. https://doi.org/10.1080/20445911.2015.1095193

Thibault, P. J. (2011). First-order languaging dynamics and second-order language: The distributed language view. Ecological Psychology: A Publication of the International Society for Ecological Psychology, 23(3), 210-245. https://doi.org/10.1080/10407413.2011.591274

Thomas, D., \& Brown, J. S. (2009). Why virtual worlds can matter. International Journal of Learning and Media, 1(1), 37-49. https://doi.org/10.1162/ijlm.2009.0008

Transana (2014). (Version 2.5) [Computer software]. Retrieved from https://www.transana.com

Van Lier, L. (2000). From input to affordance: Socio-interactive learning from an ecological perspective. In J. Lantolf (Ed.), Sociocultural Theory and Second Language Learning (pp. 245-259). New York, NY: Oxford University Press.

Van Lier, L. (2006). The ecology and semiotics of language learning: A sociocultural perspective. Boston, MA: Springer Science \& Business Media. https://doi.org/10.1007/1-4020-7912-5

Velleman, D. J. (2008). Bodies, selves. The American Imago, 65(3), 405-426. https://doi.org/10.1353/aim.0.0020

Zheng, D. (2012). Caring in the dynamics of design and languaging: Exploring second language learning in virtual spaces. Language Sciences, 34(5), 543-558. https://doi.org/10.1016/j.langsci.2012.03.010

Zheng, D., Dai, Y., \& Liu, Y. (in press). Place, identity and becomings with mobile technologies: Feminist and Chinese philosophies. International Communication of Chinese Culture.

Zheng, D., Newgarden, K., \& Young, M. F. (2012). Multimodal analysis of language learning in World of Warcraft play: Languaging as values-realizing. ReCALL, 24(3), 339-360. https://doi.org/10.1017/s0958344012000183

Zheng, D., Young, M. F., Brewer, B., \& Wagner, M. (2009). Attitude and self-efficacy change: English language learning in virtual worlds. The Computer Assisted Language Instruction Consortium Journal, 27(1), 205-231. https://doi.org/10.11139/cj.27.1.205-231

Zheng, D., Young, M. F., Wagner, M., \& Brewer, B. (2009). Negotiation for action: English language learning in game-based virtual worlds. The Modern Language Journal, 93(4), 489-511. https://doi.org/10.1111/j.1540-4781.2009.00927.x

Acknowledgements: The China World creation was supported by two funding agencies, The John D. and Catherine T. MacArthur Foundation, The Quest Atlantis International Consortium of Scholars For The Study of Gaming and Learning, and The University of Hawaii Research Relations Fund. We particularly thank the principal investigators of Atlantis Remixed project, Dr. Sasha Barab and Dr. Melissa Gresalfi, the virtual world builder, Scott Miller and all Atlantis team members. We dedicate this article to the memory of the former Director of Wo Internal Center at Punahou School, Ms. Hope Staab. We also thank the teacher and student participants, and staff support, especially Ms. Linnet Cha of Punahou School, Ms. Ying Li and Ms. Xiuling Tang of No. 90 Middle School in Changchun China.

Corresponding author: Dr. Dongping Zheng, zhengd@hawaii.edu Australasian Journal of Educational Technology (c) 2017.

Please cite as: Zheng, D., Schmidt, M., Hu, Y., Liu, M., \& Hsu, J. (2017). Eco-dialogical learning and translanguaging in open-ended 3D virtual learning environments: Where place, time, and objects matter. Australasian Journal of Educational Technology, 33(5), 107-122.

https://doi.org/10.14742/ajet.2909 